\title{
Electronic form of procurement in agricultural enterprises
}

\author{
Anna Volkonskaya ${ }^{1, *}$, Olga Pashkina $^{1}$, Natalia Galenko ${ }^{1}$, Oleg Kurlikov ${ }^{1}$, and Velta Parsova $^{2}$ \\ ${ }^{1}$ Samara State Agrarian University, 446442 Kinel, Samara region, Russia \\ ${ }^{2}$ Latvia University of Life Sciences and Technologies, Jelgava, Latvia
}

\begin{abstract}
Today in Russia the main components of digital economy are as follows: electronic trading, public services, export-import activity and constantly developing system of purchasing activity at state enterprises. The system of purchases has to conform to the requirements of modern digital technologies For this purpose at the end of 2018 the President of the Russian Federation proposed to transfer the government and corporate procurement to an electronic form. However, the analysis showed that procurement activities carried out in the form of electronic bidding in agricultural enterprises had a number of problems. These problems are related to the nature of agriculture. For example, seasonality is a key to agricultural performance. In this regard, the system of commercial transactions, including electronic trades, should be as adapted as possible to the peculiarities of agricultural production.
\end{abstract}

\section{Introduction}

Now three key components of digital economy are determined: infrastructure, which turns on hardware, the software, telecommunications; business process with elements of electronic business operations, which are implemented by means of computer networks within interactions of subjects of the virtual market; the electronic commerce assuming supply of goods through the Internet. During the era of development of high technologies, the heads of enterprises have an opportunity to use the innovation methods for optimization of business processes of an enterprise. These measures first assume implementation of programs for reducing costs, and it, in turn, emphasizes anti-recessionary aspect of actions. Economy on expenses is reached that number due to depreciation of the purchased products. As researches show, the structure of expenses of manufacturing enterprises consists on average from:

- material inputs - about $60 \%$, including raw materials and materials of 25-30\%;

- labor costs - about $20 \%$;

- assignments on social needs - about $10 \%$;

- depreciation of fixed assets - about $5 \%$;

- other cash expenditures - about $5 \%$.

Taking into account the statistical data, we can surmise that the main article of expenses in the budget of the enterprises is expenses on acquisition of materials and raw materials for production. The expenses on purchases play an essential role in forming of final cost of goods or services. Therefore, now it is so important to enterprise to develop a flexible and optimum trade and purchasing system.

One of ways of increase in efficiency of purchasing activity is carrying out electronic auction. For example, when purchasing on electronic platforms discount from the transaction makes $15-17 \%$, and in some cases reaches $40 \%$. Automation of a trade and purchasing system allows getting rid of "paperwork" and to reduce labor costs of employees to $50 \%$.

The purchases in electronic form take place on electronic trading platforms where the purchaser and the supplier meet. As a rule, customers are the enterprises and the organizations with complex, multistructural system of purchases. It is convenient to such enterprises to transfer process of purchases to an electronic form.

The enterprises and the organizations of medium and small business can also organize auction in electronic form on purchase or for sale, however, as a rule, at the similar organizations of purchase are not so big. The enterprises of these groups act more often as suppliers, otherwise, bidders. Due to electronic auction, these companies have an opportunity to expand sales market as on platforms large enterprises from different regions and sectors of economy carry out purchases. Respectively, small enterprises have an opportunity to receive the order for hundreds of millions rubles.

In addition, the companies quickly obtain information on all auction held on the subject stated by them. Besides, the electronic auction provides the fair competition, fight for obtaining the order. As the auction takes place in real time, all participants see price proposals of the competitors, but do not see names of the companies with the purpose to avoid attempts of price collusion or other abuses. After summarizing the bidding results, participants in some trading systems can study proposals of the competitors and estimate objectivity of the choice of the winner by the organizer of the auction. Thus, information transparency and openness of the auction is provided. One more essential advantage is that practically all process of participation in the electronic auction is automated.

Corresponding author: volkon2345@yandex.ru 
At this stage of information technology development the structure of lots which can be placed on the electronic trading platforms (ETP) is not limited by anything. Unambiguously it is impossible to tell when the first electronic auction in Russia was held, but the largest trading floors work since 2002 [1].

Of course, not only the companies understand economic feasibility of the electronic auction, there is also stimulation from the state within fight against corruption. The amendment of the last year to Federal Law 94 to state procurements in electronic form and recently signed Federal Law 223 on purchasing activity of the companies with state participation proved this fact.

Certainly, there are barriers to start purchasing activity on electronic trading platforms. For example, such a barrier can be represented by a psychological factor. Tendering online arouses mistrust at conservative participants of the market. The following problem is closely connected with previous: owing to the conservatism, it is difficult to people to learn something new.

Electronic procurement does not require additional professional development. Only Internet access is necessary. The companies are registered, load necessary documents. The authenticity of documents is confirmed by means of the digital signature (DS) which ensures safety of participation in the electronic auction and legal protection. According to Federal Law №1 "On the digital signature" of January 10, 2002 the DS in the electronic document admits to the equivalent autographic signature the paper document. Some electronic platforms carry out a careful inspection of all registered users. For example, they verify details and data of each company with base of Federal Tax Service.

There is one more powerful barrier - the "adjusted" schemes, the conflict of interest, which is expressed in the discrepancy of motivation of the purchasing manager and the enterprise. Such danger exists in structures where the owner does not participate in business management, and entrusts it to the hired managing director. In this regard there is "temptation" to buy from the same supplier. In this case the decision of the shareholder of the enterprise plays significant role, whether a company will carry out purchases in electronic form or not. Let us note that any enterprise interested in the future and business reputation should seek to conform to the conventional international standards. The use of electronic forms of trade demonstrates transparency of financial and economic activity of the enterprise, so, increases its investment attractiveness [2].

The use of instruments of electronic trading shows the interest of a company in innovative strategy, optimization of model of management, desire to keep up to date, remain in a vector of development of information society. Taking into account this trend of modern management, it is possible to state that sooner or later all business processes will be carried out in an electronic form. And those companies which the first will implement this method of business will get more chances to adapt to the changing external conditions and increase the efficiency and competitiveness.

\section{Materials and methods}

During the course of this study, the various existing research methods were used: analytical method, abstract and logical method, system approach, statistical and economic analysis, method of analogies, method of comparative and expert estimates, method of statistical data processing on the system of purchasing activity of the State Unitary Enterprise of the Samara region «Kupinskoye».

\section{Results}

The results of the present study demonstrate that the electronic competition as an element of purchasing activity is held from the middle of 2018. At the same time, a customer selects the winner by several criteria: price or cost of life cycle, characteristic of goods, qualification of the participant, its experience and good reputation.

The notification is published at least in 15 working days until the end of a term of requests. The participants at the same time submit two a part of the applications. Firstly, it is agreed to perform the requirements of a contract, characteristics of GWS (goods, works, services) are specified, and, secondly, information on the participant and documents, confirmatory compliance to requirements is provided. For the consideration of the first parts the commission has five days and if the initial maximum price of the contract (IMP) less than one million rubles, than only one working day is given. The second stage is the submission of final information. It occurs in the designated day on electronic trading platform (ETP). It is possible to direct the information about the price within three hours. An operator specifies all prices in the final protocol.

The final stage is the assessment of the second parts of requests. Three days is given for the commission, and when the price of a contract is less than one million, than one day is given. A participant who gained most of all points becomes the winner. It is possible to name an electronic auction new because it is the first one, which began to be carried out electronically. The terms of the publication of the notification depend on the initial price of a contract. If it is less than three million rubles, the notification should be published in seven days prior to date when the term of requests ends and if it is more than three million rubles, - in 15 days. In addition to the notification the draft contract, information card, a request sample, the specification are included in the list of the required documentation.

The participants submit applications in two parts. Firstly, a participant gives the consent delivery of goods and specifies the characteristics corresponding to those that are stated in documentation. Secondly a participant provides the data, supporting documents, papers of advantages [3].

Firstly, the commission of customers considers the first parts of requests. Seven days are given for this procedure, and if the initial price of the contract to three million rubles - one day. The data is checked for 
compliance to the requirements of documentation on purchase and the decision on the admission of each of participants is made. The following stage is the reduction of price. In appointed day all the participants reduce the price of "bid increment" online - it is 0.5 percent from five percent of its price. All the subsequent information about the price is less than previous. Later an operator of ETP enters in the protocol of 10 participants with the lowest prices.

After that, there is a consideration of the second parts of requests. According to the existing law three days are given for this procedure. As a result, the winner is the participant who offered the smallest price, and its request (both the first and second part) documentation completely meets the requirements.

Electronic request for quotation. The notification on electronic request for quotation is placed by a customer in the unified information system in 5 days until the end of a term of requests. It is necessary to attach the draft contract to the notification. Other documentation is not necessary. The application for participation consists of the technical offer. For the consideration of the submitted applications of the commission one working day is given. The winner is the participant who submitted the application meeting all requirements and offered the lowest price of the contract [4].

Electronic request for proposals. When carrying out electronic request for proposals a customer places the notification in the unified information system at least in 5 days until the end of a term of applications. Along with the notice a customer can send invitations of participation to potential suppliers. The application of a participant contains the following information:

- name and address of the legal entity;

- contacts;

- taxpayer identification number;

- the documents confirming compliance GWS to requirements;

- the documents confirming compliance of the participant to requirements;

- to paper about the right to advantages;

- the documents confirming qualification;

- offer on conditions of performance of the contract.

The researche of the mechanism of purchasing activity was conducted on the example of State Unitary Enterprise of the Samara region «Kupinskoye» (SUE SR «Kupinskoye». The enterprise carries out all government procurement on the fixed and current assets legislatively, 223-Federal Law agrees. This system practices the enterprise since 2011. All procurement procedures are performed directly under the leadership of the director together with legal department which ensures the correctness of tendering and legal legitimacy.

As it was already noted, during the implementation of the purchases a customer follows the Federal Law of July 18, 2011 № 223 "On purchases of goods, works, services as separate types of legal entities", besides the Constitution of the Russian Federation, the Civil Code of the Russian Federation, other federal laws and regulations of the Russian Federation and also the Provision on purchases of the State Unitary Enterprise of the Samara region «Kupinskoye».
The above-stated Provision contains requirements to the order of preparation and holding procurement procedures (including ways of purchase) and conditions of their application, the order of the performance of contracts and other purchases of situation connected with providing. According to the Provision, the choice of a supplier is carried out by means of the following procedures of purchase:

- competition;

- auction;

- request for quotations;

- request for proposals;

- competitive negotiations;

- purchase at the only supplier (not the competitive procedure).

The specified procedures happen, including on the Internet, and can happen on the electronic trading platforms determined by the order of the director SUE SR «Kupinskoye». The main electronic platform used by the enterprise - "OTC-tender".

There are many ways of definition of a supplier. Let us now analyze what types of purchase the procurement commission of a customer for are needed (table 1).

Table 1. Dynamics of purchases in 2014-2018 of State Unitary Enterprise of the Samara region «Kupinskoye»

\begin{tabular}{|c|c|c|c|c|c|}
\hline Way of purchase & $\mathbf{2 0 1 4}$ & $\mathbf{2 0 1 5}$ & $\mathbf{2 0 1 6}$ & $\mathbf{2 0 1 7}$ & $\mathbf{2 0 1 8}$ \\
\hline Electronic auction & 1 & 2 & 8 & 5 & 17 \\
\hline Request for proposals & - & 4 & - & - & 6 \\
\hline $\begin{array}{c}\text { Electronic request for } \\
\text { proposals }\end{array}$ & - & 1 & - & - & 1 \\
\hline Request for prices & 4 & - & 5 & 6 & 1 \\
\hline The only supplier & 1 & 1 & - & - & 1 \\
\hline $\begin{array}{c}\text { Total number of } \\
\text { purchases }\end{array}$ & $\mathbf{6}$ & $\mathbf{8}$ & $\mathbf{1 3}$ & $\mathbf{1 1}$ & $\mathbf{2 6}$ \\
\hline
\end{tabular}

According to the data of the unified information system (UIS) during the period from 2014 to 2018, the enterprise carried out 64 procurement procedures. It is possible to notice that in 2018 the number of procurement procedures was 26 that was 4 times more in comparison with 2014. At the same time the share of competitive purchases in 2018 was $96.15 \%$ that was 12,82 items more than this indicator in 2014 .

Over the years the structure of purchases considered the organizations depending on a way of carrying out is presented in Figure 1. It should be noted that throughout the period of 2014-2018 bigger specific weight in total number of the carried-out procedures is noted at an electronic auction. The priority of this way is explained by the fact that the electronic auction saves the customer's time (an independent operator registers participants), conspiracies of participants are almost excluded that is the key to the honest competition.

Figure 2 shows the largest specific weight of an electronic auction as in 2018 according to the request for proposals.

The figure 2 shows the distribution of purchases according to the choice of a supplier in 2018.

The data given below allow making the following conclusions: the sum of the prices of the contracts signed 
during purchases in 2018 was 105781,11 thousand rubles that is 68033.15 thousand rubles more in comparison with 2014. At the same time electronic auctions and requests for proposals have the greatest weight, in structure of cost of contracts (table 2).
For the analyzed period the enterprise bought more current assets, namely spare parts for the equipment. It is connected with the fact that it is not possible to foresee breakage of equipment. Unfortunately, the technical evaluation, replacement of spare parts and fuels is subject to unforeseen breakage.

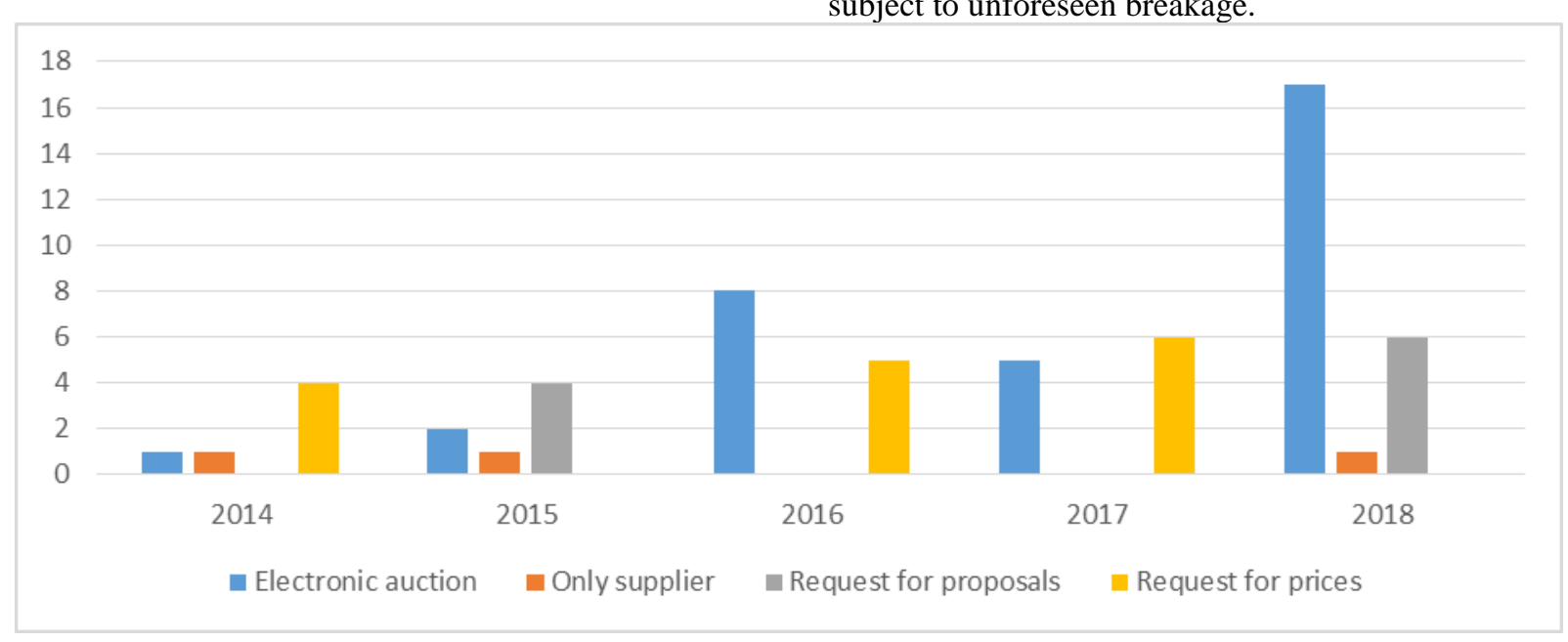

Fig. 1. Structure of purchases 2014-018 of the State Unitary Enterprise of the Samara region "Kupinskoye"

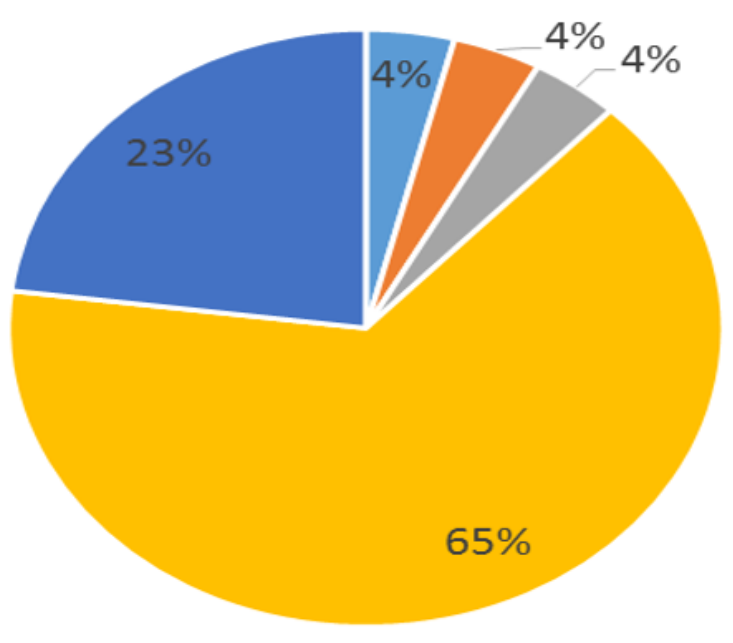

\section{= Request for prices \\ = Only supplier \\ - Request for proposals}

= Electronic request for proposals

\section{$=$ Electronic auction}

Fig. 2. Distribution of purchases according to the choice of a supplier in 2018 of the State Unitary Enterprise of the Samara region "Kupinskoye"

Table 2. Dynamics of cost of purchases the State Unitary Enterprise of the Samara region "Kupinskoye" in 2014-2018, thousand rubles.

\begin{tabular}{|c|c|c|c|c|c|}
\hline Way of purchase & 2014 & 2015 & 2016 & 2017 & 2018 \\
\hline Electronic auction & 35970.00 & 296.17 & 23628.38 & 7073.08 & 72003.80 \\
\hline Request for proposals & - & 546.00 & - & - & 1680.00 \\
\hline Electronic request for proposals & 1000.00 & 1521.99 & - & - & 133.51 \\
\hline Request for prices & 714.96 & - & 484.71 & 4930.09 & 321.89 \\
\hline The only supplier & - & 6810.00 & - & - & 31578.91 \\
\hline Total number of purchases & 37684.96 & 9174.16 & 24113.09 & 12003.17 & 105718.11 \\
\hline
\end{tabular}


It should be noted that each purchase is unique, there are not two identical purchases regarding the specification, by quantity and structure of the nomenclature. Procedural terms of holding procurement procedures are conditional, it is necessary to adhere to them, but, nevertheless, time for this or that procurement cycles always a miscellaneous. For example, there are different terms of offers for suppliers. It depends from the nomenclature, and specifics of submission of offers: whether they move on specialized electronic trading platforms or on a specialized e-mail.

Commercial and technical parts of applications can be opened at the same time and consistently that influences time of holding a procedure. In case of missing information or inaccuracy of data there is additional inquiry information to suppliers. Respectively, the time for processing of documentation increases. The direct dependence on use of a type of the draft agreement is traced: it will be the standard contract or the draft agreement of a supplier. It influences labor costs of legal and contractual service, the non-standard contract of a supplier, as a rule, it demands serious completions, the coordinated work of all responsible services of the enterprise [5].

The factors given above can have negative effect on the contracts with suppliers.

For the enterprise of the agrarian sector of economy, the loss of time is equated to loss of profit, especially during harvest works. Therefore, during harvest works, agricultural machinery and cars often break, and spare parts are purchased by means of an electronic auction. This procedure rather long in itself and can last to 55 days. As a result of the purchase the contract was signed, however it occurred after the end of a harvest season. As a result, the enterprise lost 105 tons of seed of wheat. However, it is not always possible to plan or foresee breakage of equipment, despite a technical evaluation. During harvest works, breakage of the equipment can lead to serious losses.

The enterprises in Russia have to buy the most part of current and fixed assets by means of purchases. Therefore, it is necessary to do everything possible for the reduction of time for purchase. In our opinion, there is a way to solve this problem: it is necessary to make amendments to the Provision of the SUE SR «Kupinskoye».

The essence of our offer consists in the use of "Purchase according to the summary price list in electronic form" and subsequently the conclusions of the "frame" contract. The choice of offers of the summary price list is a competitive way of the choice of a supplier without tendering. In this case, the procurement commission (allowed to a procurement procedure) chooses a supplier who offered the smallest price and the best terms of performance of the contract for delivery of goods, performance of work or rendering services from the list of the suppliers [6].

The way is convenient if, first, it is necessary to compare participants by price and not-price criteria (qualification, experience, or to other conditions specified in documentation on purchase by the choice of offers of the summary price list). Secondly, the choice of a supplier (a contractor, a performer) is carried out in shorter terms than during other ways of purchase.

The procedure of the choice of offers of the summary price list is not a competition, or an auction and its carrying out is not regulated by Articles 447 - the $449^{\text {th }}$ of the Civil code of the Russian Federation. This procedure of open request for proposals is also not a public competition and is not regulated by Articles 1057-1061 of the Civil Code of the Russian Federation. Thus, this procedure does not impose legal obligations for obligatory signing of the contract with the winner of the choice of offers of the total price list or other participants.

Any person, who set properly issued price list on the electronic platform chosen by a customer, can participate in a procedure of procurements which are conducted at the choice of a supplier on the basis of the analysis and comparison of offers of the summary price list [7].

The following information must be posted on the website of a customer:

1) Name, location, postal address and e-mail address, contact phone number and customer's fax;

2) An order of admission of bidders to participation in the procedure of the choice of offers of the summary price list;

3) An order of signing of the contract (the frame contract) between the customer and the supplier allowed participating in a procurement procedure.

The list of documents submitted by the bidder necessary for adoption by the customer of the decision on admission to participation in the procedure:

1) Questionnaire of the participant;

2) The documents confirming powers of the person for implementation of actions on behalf of the participant;

3) the copies of constituent documents of the participant, the copy of the Russian Federation citizen passport (for natural persons);

4) copies of the document confirming compliance of participants to requirements of the legislation of the Russian Federation (the copy of licenses and other allowing documents);

5) the documents confirming compliance of the participant of a procurement procedure to requirements of documentation of a procurement procedure;

6) other documents.

The person willing to participate in a procedure of the choice of offers of the summary price list sends to the customer the application for participation and the documents stated above [8].

Order of "the choice of sentences of the summary price list" procedure

1. The procedure of the choice of sentences of the summary price list is defined by the customer proceeding from his requirements in GWS.

2. The customer on ETP creates in electronic form the request (a request list) which may contain unlimited number of positions of GWS.

3 . On the basis of the received prices from potential suppliers, the commission of the customer determines by each position of products the supplier who offered the best terms of delivery to products. At the same time, the 
smallest price of products on a specific position is not the only condition of delivery on which suppliers are selected. The commission has the right along with the smallest price to consider also other terms of delivery, such as delivery time, residual expiration date of goods, terms of payment (a payment delay, prepayment), goods quality assurances, the vendor, etc.

4. Results of work of the commission on the choice of sentences of the summary price list are regulated by the protocol and remain in electronic form on the customer's resource.

5. The commission chooses suppliers who offer the best terms of delivery of goods on each position. After that the customer suggests winners to sign the contract. On the basis of this contract suppliers will deliver GWS on the basis of tasks from the customer.

It should be noted that the customer has the right to refuse at any stage purchase execution by the choice of sentences of the summary price list, without posting the message about it on the official site [9].

As it was mentioned earlier, as a result of a procurement procedure, we suggest signing "the frame agreement" or "the contract with open conditions". The concept of the frame contract was published in the civil legislation in 2015. The contract defining the general conditions of obligations relationship of the parties, which can be concretized and specified, by the parties by the conclusion of separate contracts, submission of requests of one of the parties or otherwise on the basis or in pursuance of the frame contract is recognized as the frame contract.

The customer can define the list of purchases to the equipment without pointing exact quantity to spare parts. The customer sets in the notification and documentation on purchase the maximum price of unit GWS also the maximum price of the contract. In the future, the actual volume of the delivered GWS will be defined on the basis of the actual need of the customer. The price of the contract should not exceed the maximum price established in the contract.

The completion date of the frame contract comes after delivery of the volume of products equal limit (IMPs limit), or on the expiration, specified in the frame contract.

This innovation has both positive and negative sides. In our opinion, the negative side is a complexity of the procedure at the introduction stage. At this stage, it is necessary to make amendments to the Provision on purchase, to place the information on the portal of the Unified information system, to make the summary list of GWS for potential suppliers.

The main positive side of this method is a reduction of time. As we already noted, the customer can carry out the procedure in the end of the year, and next year the application in process of receipt of "problems" is sent to customers [10].

At the same time, the customer specifies term in the contract during which the supplier is obliged to deliver goods or to render work/service after emergence of the application. This condition will help to reduce time too.

One more important positive side of our innovation is the price. This price will be the same during the entire period of operation of the frame contract with the contractor.

It should be noted that the customer a year later should restart this procedure, for updating the list of suppliers. At this stage, if the contract with the acting supplier is prolonged, the additional agreement to the contract on the change in price will be concluded.

Any innovation must affect work of the enterprise positively. As a result, the extent of the missed benefit is 855 thousand rubles. Therefore, after modification of purchasing activity of SUE SR «Kupinskoye» the negative profitability of sales can be reduced by 0,6 per cents.

\section{Conclusion}

The results of the research showed that:

- Electronic trades in the agricultural production system are the most convenient tool of the agricultural producer. It maximizes the target audience in a single source.

- The system of digital procurement for the agricultural enterprise, according to the analysis of the State Unitary Enterprise of the Samara region «Kupinskoye», will allow reducing the time of procurement procedure as much as possible in order to avoid financial losses.

- Application in the agricultural enterprise of a new method of electronic procurement - price purchase or purchase under a single price list with conclusion of a master contract will allow reducing time. This will have a positive impact on the performance of the enterprise.

- When implementing the above-mentioned form of procurement at the State Unitary Enterprise of the Samara region «Kupinskoye», the need to launch a new procurement procedure every time disappears. This will save time and reduce losses during fieldwork.

\section{References}

1. E.A. Osadchy, E.M. Akhmetshin, E.F. Amirova, T.N. Bochkareva, Yu.Yu. Gazizyanova, A.V. Yumashev, Financial statements of a company as an information base for decision-making in a transforming economy Europ. Res. Stud. J. 21(2), 339-350 (2018)

2. E.M. Akhmetshin, A.V. Pavlyuk, A.S. Kokorev, T.G. Lazareva, E.I. Artemova, J. of applied econ. Sci. 8(62), 2309-2322 (2018)

3. O.V. Mamai, A.A. Penkin, I.S. Kurmaeva, A.L Mishanin, S.V. Pertsev, Government regulation of the economy: why it is effective Res. J. of Pharm., Biolog. and Chem. Sci. 9(5), 1269-1275 (2018)

4. V.G. Vasin, A.N. Burunov, A.V. Vasin, V.A. Milyutkin, N.V. Vasina, R.N. Bagautdinov, A.V. Novikov, Res. J. of Pharm., Biolog. and Chem. Sci. 5, 1248-1260 (2018)

5. V.A. Milyutkin, V.E. Buksman, Machinery and equipment for the village 7, 10-12 (2018) 
6. P.A. Chekmarev, S.V. Obushhenko, V.B. Trocz, N.M. Trocz, The achievements of science and technology APK 8, 28-31 (2018)

7. V.G. Kutilkin, S.N. Zudilin, Agriculture 2, 19-22 (2018)

8. M.A. Mastepanenko, S.Z. Gabriyelyan, I.N. Vorotnikov, S.V. Mashkov, E.V. Kulaev, Res. J. of Pharm., Biolog. and Chem. Sci. 6, 1846-1851 (2018)
9. A.M. Petrov, M.A. Kanaev, Yu.A. Savelev, S.A. Vasilev, E.S. Kanaeva, Res. J. of Pharm., Biolog. and Chem. Sci. 5, 925-934 (2018)

10. A.G. Volkonskaya, N.N. Galenko, O.I. Kurlykov, Administrative problems of the agrarian sector in Current probl. of agrar. Sci. and way of their decision: collec. of sci. works (Kinel, 2016) 